\title{
Conversion from conventional esophageal endoscopic submucosal dissection to the gel immersion method
}

During conventional endoscopic submucosal dissection (ESD), increased intragastric pressure due to insufflation sometimes causes discomfort and pain to the patient. However, gel immersion endoscopy (GIE), which has been developed to improve intraoperative visualization and identify the bleeding point easily [1-4], may reduce patient discomfort because it can be performed under low pressure [5]. Here, we report a case of ESD of superficial esophageal cancer performed via GIE, using a novel gel product (VISCOCLEAR; Otsuka Pharmaceuticals Factory, Inc., Tokyo, Japan), for reducing patient discomfort.

A 65-year-old man was referred to our hospital for resection of superficial esophageal cancer. The lesion was flat, $45 \mathrm{~mm}$ in diameter, located on the left midesophageal wall, and involving twothirds of the circumference ( $>$ Fig. 1). Although conventional ESD was performed under sufficient sedation using dexmedetomidine, midazolam, and pethidine, the patient remained irritable due to the increased intragastric pressure after $\mathrm{CO}_{2}$ insufflation. It was not possible to continue the procedure safely. Therefore, after circumferential incision and partial submucosal dissection on the proximal side, we converted to gel immersion ESD using VISCOCLEAR, which does not require high intragastric pressure. $\mathrm{CO}_{2}$ insufflation was turned off and the gel was injected through the BioShield irrigator (US Endoscopy, Mentor, Ohio, United States) ( $\triangleright$ Fig. 2). After conversion to gel immersion ESD, the patient's irritability disappeared. We secured a good approach to the submucosal layer due to the gel's buoyancy ( $>$ Fig. 3 ). The bleeding slowed due to the gel's viscosity and further injection of the gel resulted in good visualization ( $>$ Fig.4). Therefore, we were able to secure hemostasis quickly and easily. The tumor was completely excised without esophageal perforation or aspiration of the gel by the

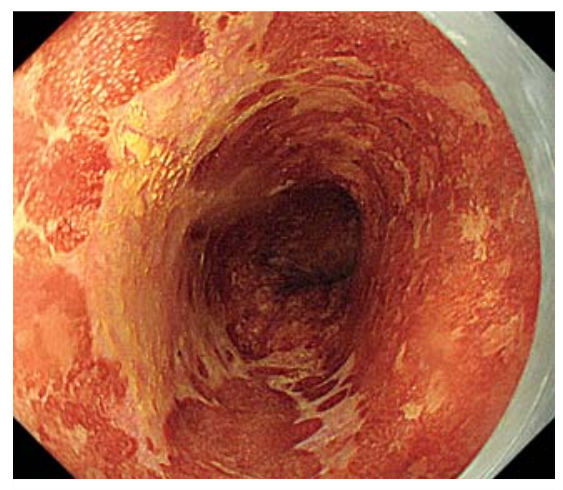

- Fig. 1 Endoscopic image showing superficial esophageal cancer, which was a flat lesion, $45 \mathrm{~mm}$ in diameter, located on the left midesophageal wall, and involving two-thirds of the circumference.

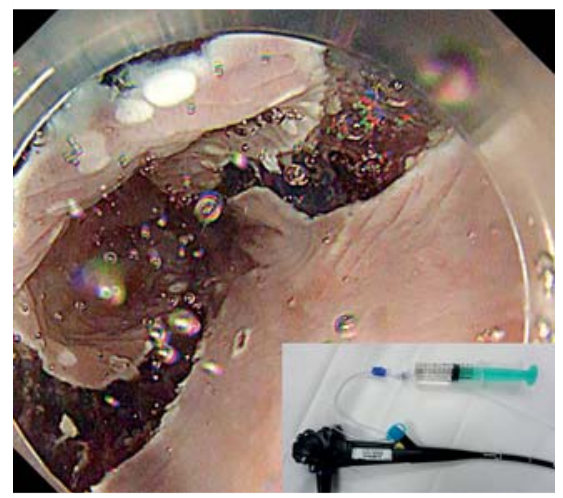

- Fig. 2 Injection of the gel through the BioShield irrigator.

patient ( $>$ Fig. 5 and $>$ Video 1 ). Gel immersion esophageal ESD using a novel gel product (VISCOCLEAR) may be a safe and effective procedure.

\section{Competing interests}

The authors declare that they have no conflict of interest.

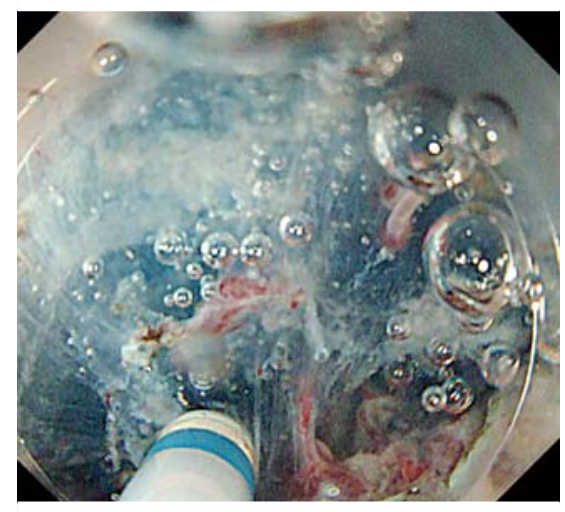

- Fig. 3 A good approach to the submucosal layer was secured due to the gel's buoyancy.

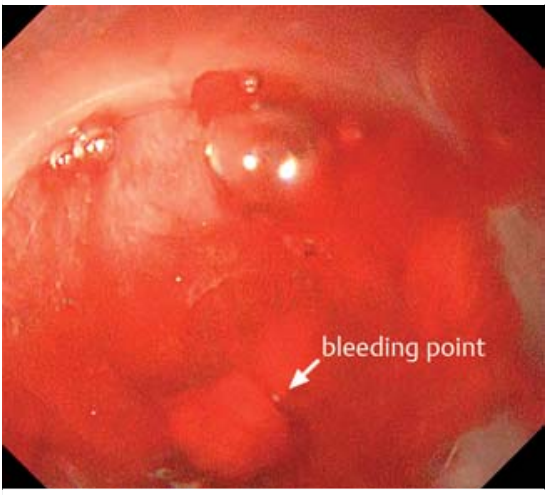

- Fig. 4 Bleeding occurred slowly due to the gel's viscous nature and further injection of the gel enabled good visualization (white arrow).

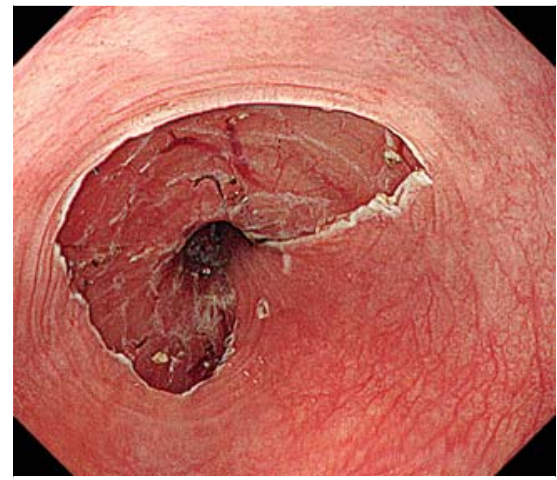

Fig. 5 Mucosal defect without perforation. 


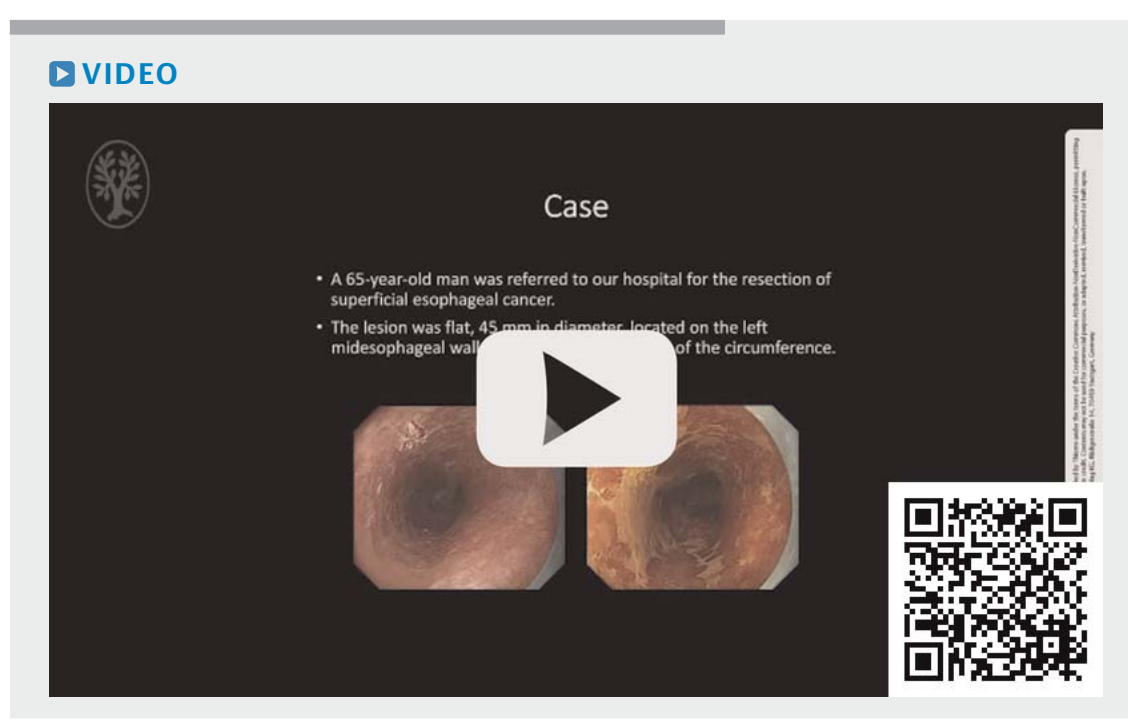

- Video 1 Successful gel immersion esophageal endoscopic submucosal dissection using a novel gel product (VISCOCLEAR).

The authors

Yuya Nakano', Tomoaki Tashima', Ryuhei Jinushi ${ }^{1}$, Rie Terada ${ }^{1}$, Yumi Mashimo', Tomonori Kawasaki ${ }^{2}$, Shomei Ryozawa ${ }^{1}$

1 Department of Gastroenterology, Saitama Medical University International Medical Center, Saitama, Japan

2 Department of Pathology, Saitama Medical University International Medical Center, Saitama, Japan

\section{Corresponding author}

Tomoaki Tashima, MD, PhD

Department of Gastroenterology, Saitama Medical University International Medical Center, 1397-1 Yamane, Hidaka City, Saitama 350-1298, Japan Fax: +81-42-984-4589 t.tashima1981@gmail.com

\section{References}

[1] Yano T, Nemoto D, Ono K et al. Gel immersion endoscopy: a novel method to secure the visual field during endoscopy in bleeding patients (with videos). Gastrointest Endosc 2016; 83: 809-811

[2] Miura Y, Yano T, Takezawa T et al. Gel immersion endoscopy simplifies hemostasis during endoscopic submucosal dissection using the pocket-creation method. Endoscopy 2018; 50: E294-E295

[3] Akasaka T, Takeuchi Y, Ishida $\mathrm{H}$ et al. A novel gel immersion technique using a bipolar needle-knife in endoscopic submucosal dissection for superficial gastrointestinal neoplasms. Ann Gastroenterol 2018; 31: 247

[4] Miyamoto S, Suzuki K, Kinoshita K. Efficiency of a novel gel product for duodenal ulcer bleeding. Dig Endosc 2021; 33: e63-e64

[5] Yano K, Yano T, Nagayama M et al. Hemostasis of an actively bleeding lesion at the ileocecal valve by low-pressure endoscopy using the gel immersion technique. VideoGIE 2021; 6: 184-186

\section{Bibliography}

Endosc Int Open 2021; 09: E1756-E1757

DOI 10.1055/a-1578-2543

ISSN 2364-3722

(C) 2021. The Author(s).

This is an open access article published by Thieme under the terms of the Creative Commons Attribution-NonDerivativeNonCommercial License, permitting copying and reproduction so long as the original work is given appropriate credit. Contents may not be used for commercial purposes, or adapted, remixed, transformed or built upon. (https:// creativecommons.org/licenses/by-nc-nd/4.0/)

Georg Thieme Verlag KG, Rüdigerstraße 14, 70469 Stuttgart, Germany

\section{다 (i) $\odot=$}

